\title{
A New Publisher for Clinical Orthopaedics and Related Research
}

With this issue of Clinical Orthopaedics and Related Research we begin with a new publisher, Springer, long and internationally known for their high-quality publications. The Association of Bone and Joint Surgeons, the owners of CORR, and the CORR Board of Trustees deliberated on the proposals of numerous excellent publishers prior to making this decision. We have enjoyed working with Springer during the transition and look forward to implementing new online features available with their technical capabilities.

Readers will immediately notice some changes in the cover and format of our articles. Our content will remain largely the same, although with this issue we are introducing several new features. In particular, we are creating a "Residents' Corner," which will appear at the back of each month's issue.

As most readers know, CORR was hardbound from 1953 through 2003. It appeared initially as two volumes per year and over the years the number of volumes per year increased until 1986, by which time 12 volumes per year were published. At that time, the publisher elected to maintain the tradition of renumbering each month's offering as a separate volume, bringing us to volume 466 . In recent years this has caused some problems with those who use reference managing software. Therefore beginning with this issue, the volume number will be retained throughout the year and the issues will be numbered 1-12 each year.

We wish to thank the many dedicated individuals with whom we worked at Lippincott Williams \& Wilkins, our publisher since 1953, for their help in developing CORR into a high quality journal.

We also thank our authors, reviewers, and symposia guest editors: through their submissions and reviews, we have been afforded the content that has created CORR. Finally, the journal could not have been published without our devoted full-time staff of editorial associates and copyeditors, and we owe them our gratitude.

Richard A. Brand, MD Editor-in-Chief

Guy T. Vise Jr., MD Chair, CORR Board of Trustees

Randall E. Marcus, MD President, ABJS 